\title{
Red manganese phthalocyanines from highly hindered hexadecaalkoxyphthalocyanines
}

\author{
Clifford C. Leznoff* ${ }^{*}$ L. Scott Black, Annette Hiebert, Patrick W. Causey, \\ Dharamdat Christendat, A.B.P. Lever * \\ Department of Chemistry. York University, Toronto, Ont.. Camada M3J IP3 \\ Recejved 22 September 2005; accepted 17 October 2005 \\ Available online 20 December 2005 \\ Dedicated to Brian James on the occasion of his 70th birthday.
}

\begin{abstract}
Highly hindered magnesium and metal-free green $1,2,3,4,8,9,10,11,15,16,17,18,22,23,24,25$-hexadecaneopentoxyphthalocyanine and $1,2,3,4,8,9,10,11,15,16,17,18,22,23,24,25$-hexadeca(cyclohexylmethyloxy)phthalocyanine were prepared via magnesium 1 -octanolate and 3,4,5,6-tetraneopentoxyphthalonitrile or 3,4,5,6-tetra(cyclohexylmethyloxy)phthalonitrile. Treatment of the metal-free phthalocyanine with $\mathrm{Mn}(\mathrm{OAc})_{2}$ yielded deep red manganese(III) hexadecaalkoxy phthalocyanines. Electrochemical and spectroelectrochemical studies led to the characterization, in solution, of a series of species in a range of different manganese and phthalocyanine oxidation states.
\end{abstract}

웅 2005 Elsevier B.V. All rights reserved.

Keywords: Phthalocyanine; Manganese; ZINDO; Spectroelectrochemistry; Electrochemistry; Electronic spectra; Hexasubstituted

\section{Introduction}

Phthalocyanines (Pcs) are typically purple, blue or green macrocyclic compounds similar in structure to tetraazaporphyrins, but having four additional fused benzo rings $[1,2]$. The inertness of Pcs is well known [3], but their classical use as dyes [3] is now overshadowed by other applications taking advantage of the intense absorption of the Q-band, normally between 670 and $730 \mathrm{~nm}$. Highly red-shifted analogs of Pcs, having additional benzo groups attached to the Pc benzo groups (the naphthalocyanines and even anthracenocyanines (4]) are usually difficult to prepare, highly insoluble, and prone to decomposition [5]. It has long been known that Pcs containing electron-donating substituents at the $1,4,8,11,15,18,22,25$ positions (the non-peripheral

\footnotetext{
Corresponding author. Tel.: $+14167362100 \times 33838$; fax: +416735 5936.

E-mail addresses: leznofi@yorku.ca (C.C. Leznoff), blever@yorku.ca (A.B.P. Lever).
}

substituents) show some red-shifts of the Pc chromophore, but that only minor shifts occur due to substituents placed at the $2,3,9,10,16,17,23,24$ positions (the peripheral substituents) $[6-8]$. On the other hand some hexadecaalkoxysubstituted Pc nickel compounds exhibited enhanced red shifts, showing a Q-band shifted to as long a wavelength as $745 \mathrm{~nm}$ [9]. It appears that the substituents at the peripheral positions buttress the substituents at the non-peripheral positions effectively making the non-peripheral substituents bulkier.

In this spirit, in previous research in the Leznoff group, very bulky neopentoxy groups have been used to cause a red-shift in the Q-band region of the UV-Vis spectra of Pcs [10], such that hexadecaneopentoxyphthalocyanine nickel(II) had the lowest energy Q-band yet recorded for an alkoxy-substituted metallated $\mathrm{Pc}$, at $758 \mathrm{~nm}$. In addition, these bulky peripheral groups disrupt $\pi$-stacking between macrocycles and therefore increase the solubility of the substituted Pcs even in non-polar solvents such as hexanes. Although the preparation of hexadecaneopentoxy 
phthalocyanine nickel has been described previously [10], a method for the synthesis of analogous Pcs containing different metal cations proved difficult. It was thought that if the bulky metal-free Pc were prepared, it would allow various metallated Pcs to be prepared by refluxing in the presence of metal salts.

As Hanack had shown [9] that only bulky Pcs containing nickel can be readily prepared and since removal of the nickel is difficult to accomplish without decomposition, other metallated or metal-free bulky alkoxy Pcs were not easily prepared. We tried many established methods [7] as well as newer methods [11-14] usually to no avail. Finally, we have succeeded in preparing bulky alkoxy-substituted metal-free and metallated Pcs, including unusual red manganese Pcs and have communicated this in some patents $[15,16]$. The Cook [17] and Kobayashi [18] groups have also recently described some red phthalocyanines, the former having eight sulfur substituents and a lead core, while the latter had eight phenyl substituents and a tin core. In this paper, we report the full details of the red phthalocyanines, bearing 16 bulky alkoxy substituents and a manganese core.

\section{Experimental}

\subsection{Materials}

Solvents, dimethylformamide (DMF) and tetrahydrofuran (THF), were obtained from Sigma-Aldrich Chemical and used as received. Reagent grade tetrahydrofuran was distilled, under nitrogen, over sodium ribbon using benzophenone as an indicator. All other solvents of reagent grade were purchased from Sigma-Aldrich and used as received.

Tetra- $n$-butylammonium perchlorate (TBAP) was purchased from Fluka Chemika, and was purified by recrystallisation from ethanol and dried under vacuum for 2 days prior to use.

\subsubsection{3,4,5,6-Tetraneopentoxyphthalonitrile (2)}

Compound 2 was prepared according to a previously described procedure [10].

\subsubsection{3,4,5,6-Tetra(cyclohexylmethyloxy) phthalonitrile (3)}

To 3,4,5,6-tetrafluorophthalonitrile (1) $(0.5 \mathrm{~g}, 2.5 \mathrm{mmol})$, dissolved in $N, N$-dimethylformamide (DMF) (15 mL), was added cyclohexylmethanol $(7.0 \mathrm{~g}, 62 \mathrm{mmol})$ and potassium carbonate $(8.6 \mathrm{~g}, 62 \mathrm{mmol})$. The mixture was heated to $110^{\circ} \mathrm{C}$ for 5 days. After this period, the reaction mixture was poured into water $(200 \mathrm{~mL})$ and extracted with ether $(3 \times 50 \mathrm{~mL})$. The combined ether layers were washed with water $(100 \mathrm{~mL})$ followed by saturated brine $(100 \mathrm{~mL})$. After drying over sodium sulfate the solvent was removed and the remaining oily material purified by flash silica gel chromatography using a mixture of dichloromethane/ methanol $=20: 1$ as the eluting solvent. The first fraction was collected and the solvent was evaporated to give in
$70 \%$ yield, $1.0 \mathrm{~g}$ of 3 as a yellow solid, m.p. $70-72{ }^{\circ} \mathrm{C},{ }^{1} \mathrm{H}$ NMR $\left(400 \mathrm{MHz}, \mathrm{CDCl}_{3}, 293 \mathrm{~K}\right): \delta 3.93$ (d, $J=6 \mathrm{~Hz}$, $2 \mathrm{H}), 3.88(\mathrm{~d}, J=6 \mathrm{~Hz}, 2 \mathrm{H}), 1.8(\mathrm{~m}, 12 \mathrm{H}), 1.2(\mathrm{~m}, 10 \mathrm{H})$. IR (KBr): $v_{\max }, \mathrm{cm}^{-1} 2231 \mathrm{~cm}^{-1}$ (CN): HRMS Calc. for $\mathrm{C}_{36} \mathrm{H}_{52} \mathrm{~N}_{2} \mathrm{O}_{4}: 576.3927$; found $\mathrm{M}^{+}=576.3931$; Anal. Calc. for $\mathrm{C}_{36} \mathrm{H}_{52} \mathrm{~N}_{2} \mathrm{O}_{4}: \mathrm{C}, 74.96 ; \mathrm{H}, 9.09 ; \mathrm{N}, 4.86$; Found: $\mathrm{C}$, $74.9 ; \mathrm{H}, 9.16 ; \mathrm{N}, 5.06 \%$.

2.1.3. $1,2,3,4,8,9.10,11,15,16,17,18,22,23,24,2.5$ -

Hexadecaneopentoxyphthalocyaninato magnesium(II) (4) [NeoPc(2-) Mg]

Magnesium alkoxides of long chain alcohols are not readily synthesized from the metal [19], but can be easily prepared from a suitable Grignard reagent. To approximately $2 \mathrm{~mL}$ of 1 -octanol was added $1.5 \mathrm{~mL}$ of $1.0 \mathrm{M}$ phenyl magnesium bromide solution in THF, during which heat was liberated. After $15 \mathrm{~min}$ of stirring to ensure the complete reaction of the Grignard reagent, 3,4,5,6-tetraneopentoxyphthalonitrile was added, and the reaction mixture was heated to $120^{\circ} \mathrm{C}$ for a period of 4 days. The resulting green material: UV-Vis (THF) $\lambda_{\max } / \mathrm{nm}(\log \varepsilon)$ 754 (5.30), 672 (4.62), 366 (4.70), 330 (4.77); 'H NMR $\left(400 \mathrm{MHz}\right.$, toluene- $\left.d_{8}, 333 \mathrm{~K}\right) \delta 5.14(\mathrm{~s}, 16 \mathrm{H}), 4.53(\mathrm{~s}$, $16 \mathrm{H}), 1.39(\mathrm{~s}, 72 \mathrm{H}), 1.28(\mathrm{~s}, 72 \mathrm{H})$; MALDI-MS for $\mathrm{C}_{112} \mathrm{H}_{176} \mathrm{~N}_{8} \mathrm{O}_{16} \mathrm{Mg}\left(\mathrm{m} / z\right.$ intensity, \%) $1914.0\left(\mathrm{M}^{+}, 100\right)$; Anal. Calc. for $\mathrm{C}_{112} \mathrm{H}_{176} \mathrm{~N}_{8} \mathrm{O}_{16} \mathrm{Mg}$ : C, 70.25; $\mathrm{H}, 9.26 ; \mathrm{N}$, 5.85; Found: C, 70.18; H, 9.62; N, 5.84\%.

2.1.4. $1,2,3,4,8,9,10,11,15,16,17,18,22,23,24,25-$

Hexadeca(cyclohexylmethyloxy) phthalocyaninato magnesium(II) (5) $[\mathrm{CyHxPc}(2-) \mathrm{Mg}]$

To approximately $2 \mathrm{~mL}$ of 1-octanol, was added $1.0 \mathrm{~mL}$ of $1.0 \mathrm{M}$ phenyl magnesium bromide solution in THF. After 15 min of stirring to ensure the complete reaction of the Grignard reagent to form the magnesium alkoxide, $250 \mathrm{mg}$ of 3,4,5,6-tetra(cyclohexylmethyloxy)phthalonitrile (3) was added. The reaction mixture was heated to $120^{\circ} \mathrm{C}$ for $24 \mathrm{~h}$. The resulting material was transferred to test tubes and precipitated out of solution using acidified $95 \%$ ethanol:water. After centrifuging and removing the ethanol, the precipitate was washed twice with water to give $130 \mathrm{mg}$ of a green solid in $51 \%$ yield: UV-Vis (THF) $\lambda_{\max } / \mathrm{nm}(\log \varepsilon)$ 742 (4.9), 676 (4.3), 364 (4.7), 328 (4.7); ${ }^{1} \mathrm{H}$ NMR (400 MHz, toluene- $\left.d_{8}, 335 \mathrm{~K}\right) \delta 5.14(\mathrm{~d}, J=5.8 \mathrm{~Hz}, 16 \mathrm{H}), 4.57(\mathrm{~d}$, $J=5.8 \mathrm{~Hz}, 16 \mathrm{H}), 0.87-2.70(\mathrm{~m}, 176 \mathrm{H}) ;$ MALDI-MS for $\mathrm{C}_{144} \mathrm{H}_{208} \mathrm{~N}_{8} \mathrm{O}_{16} \mathrm{Mg}$ (m/z intensity,\%) $2330.1\left(\mathrm{M}^{+}, 100\right)$; MALDI-MS: $\mathrm{M}^{+}=2330.1$; ${ }^{1} \mathrm{H}$ NMR: $5.2(\mathrm{~s}, 16 \mathrm{H}), 4.6(\mathrm{~d}$, 16H) and many other multiplets.

A high-temperature NMR study was done on this Pc: NMR measurements were taken at different temperatures from 300 to $355 \mathrm{~K}$ in toluene- $d_{8}$. This study shows remarkable changes in the $\mathrm{OCH}_{2}$ region. At $300 \mathrm{~K}$ one set of protons is represented by a doublet at $4.56 \mathrm{ppm}(J=4.5 \mathrm{~Hz}$, $16 \mathrm{H}$, peripheral) and the other one by a broad singlet at $5.18 \mathrm{ppm}$. As the temperature increases to $355 \mathrm{~K}$, both peaks become sharper and the singlet develops into a doublet at $5.13 \mathrm{ppm}(J=4.2 \mathrm{~Hz}, 16 \mathrm{H}$, non-peripheral). 
2.1.5. Metal-free 1,2,3,4,8,9,10,11,15.16,17,18,22,23,24,25Hexadecaneopentoxyphthalocyanine (6) [ $\mathrm{NeoPc}(2-) \mathrm{H}_{2}$ ]

The magnesium phthalocyanine (4) was dissolved in $5 \mathrm{~mL}$ of glacial acetic acid and refluxed for 3 days. The process provided a $68-80 \%$ yield of metal-free $1,2,3,4,8,9,10,11,15,16,17,18,22,23,24,25$-hexadecaneopentoxyphthalocyanine (6). Definite changes were observed in the Q-band region of the UV-Vis spectrum which indicated pure metal-free phthalocyanine 6: UV-Vis (THF) $\lambda_{\max } / \mathrm{nm}$ ( $\log \varepsilon) 784$ (5.13), 764 (5.13), 686 (4.55), 398 (4.58), 328 (4.78); ' ${ }^{\mathrm{H}} \mathrm{NMR}(400 \mathrm{MHz}$, toluene-ds, $355 \mathrm{~K}) \delta 4.86(\mathrm{~s}$, $16 \mathrm{H}), 4.46(\mathrm{~s}, 16 \mathrm{H}), 1.33(\mathrm{~s}, 72 \mathrm{H}), 1.19(\mathrm{~s}, 72 \mathrm{H})$; MALDI-MS for $\mathrm{C}_{112} \mathrm{H}_{178} \mathrm{~N}_{8} \mathrm{O}_{16}(\mathrm{~m} / z$ intensity,\%) 1891.9 $\left(\mathrm{M}^{+}, 100\right)$; Anal. Calc. for $\mathrm{C}_{112} \mathrm{H}_{178} \mathrm{~N}_{8} \mathrm{O}_{16}: \mathrm{C}, 71.07 ; \mathrm{H}$, 9.48; N, 5.92. Found: C, $71.29 ; \mathrm{H}, 9.94 ; \mathrm{N}, 5.98 \%$.

2.1.6. Metal-free $1,2,3,4,8,9,10,11,15,16,17,18,22,23,24,25$ hexadeca (cyclohexylmethyloxy) phthalocyanine (7) $\left[\mathrm{CyHxPc}(2-) \mathrm{H}_{2}\right]$

The magnesium hexadeca(cyclohexylmethyloxy)phthalocyanine $(125 \mathrm{mg})$ was dissolved in glacial acetic acid $(4 \mathrm{~mL})$ and refluxed for 4 days. It is advisable to follow the reaction by UV to make sure that it is completed, so that the single absorption peak in the Q-band of the PcMg is replaced by the red-shifted double absorption peak of the metal-free Pc. After this period the reaction mixture was transferred to test tubes and precipitated out of solution using $95 \%$ ethanol/water. After centrifuging and removing the ethanol, the precipitate was washed twice with methanol. This procedure gives a light green solid in $77 \%$ yield (95 mg). MALDI-MS: $\mathrm{M}^{+}=2308.1$; UV-Vis: $\lambda_{\max } / \mathrm{nm}$ ( $\log \varepsilon) 766$ (5.0), 682 (4.4), 390 (4.4), 324 (4.6); 'H NMR: $5.1(\mathrm{~d}, 16 \mathrm{H}), 4.6(\mathrm{~d}, 16 \mathrm{H})$ and many other multiplets. Anal. Calc. for $\mathrm{C}_{144} \mathrm{H}_{210} \mathrm{~N}_{8} \mathrm{O}_{16}: \mathrm{C}, 74.90 ; \mathrm{H}, 9.17 ; \mathrm{N}, 4.85$. Found: C, $75.13 ; \mathrm{H}, 9.57 ; \mathrm{N}, 4.69 \%$.

\subsection{7. $1,2,3,4,8,9,10,11,15,16,17,18,22,23,24,25-$ \\ Hexadecaneopentoxyphthalocyaninato manganese( (II) acetate (8) [NeoPc(2-) Mn (OAc)]}

Metal-free hexadecaneopentoxyphthalocyanine (6) $(80 \mathrm{mg})$ was refiuxed in DMF $(3 \mathrm{~mL})$ with excess manganese(II) acetate. After $48 \mathrm{~h}$, the reaction mixture was allowed to cool to room temperature, and the reddishbrown reaction mixture was purified by flash silica gel column chromatography using toluene as the eluting solvent. The resulting amorphous red solid was then further purified by size-exclusion chromatography using toluene as the eluent. A final flash silica gel column was carried out, using toluene as the eluting solvent to give the desired manganese phthalocyanine 8 as a red solid in $14 \%$ yield (12 mg): m.p. $>300^{\circ} \mathrm{C}$ : UV-Vis (THF) $\lambda_{\max } / \mathrm{nm}(\log \varepsilon$ ) 827 (4.8), 740 (4.2), 570 (4.15), 465sh, 413(4.4); ${ }^{1}$ H NMR $\left(400 \mathrm{MHz}\right.$, toluene-d $\left.d_{8}, 340 \mathrm{~K}\right) \delta 4.48(\mathrm{~b}, 4 \mathrm{H}), 1.48(\mathrm{~s}$, $18 \mathrm{H}), 1.13(\mathrm{~m}, 18 \mathrm{H})$; MALDI-MS for $\mathrm{C}_{114} \mathrm{H}_{179} \mathrm{~N}_{8} \mathrm{O}_{18} \mathrm{Mn}$ $\left(\mathrm{m} / \mathrm{z}\right.$ intensity, \%) $1945.4\left(\mathrm{M}^{+}\right.$-OAc, 100); Anal. Calc. for acetate salt $\mathrm{C}_{114} \mathrm{H}_{179} \mathrm{~N}_{8} \mathrm{O}_{18} \mathrm{Mn}: \mathrm{C}, 68.30 ; \mathrm{H}, 9.00 ; \mathrm{N}$, 5.59. Found: C, $68.46 ; \mathrm{H}, 9.69 ; \mathrm{N}, 5.28 \%$.
2.1.8. $1,2,3,4,8,9,10,11,15,16,17,18,22,23,24,25$ -

Hexadeca (cyclohexylmethyloxy) phthalocyaninato manganese (III) acetate (9) [CyHxPc(2-) Mn(OAc)]

Metal-free hexadeca(cyclohexylmethyloxy)phthalocyanine $(25 \mathrm{mg})$ was dissolved in DMF $(1-2 \mathrm{~mL})$ with a large excess of manganese(II) acetate. The mixture was heated to $130^{\circ} \mathrm{C}$ for $48 \mathrm{~h}$. It is advisable to follow the reaction by UV-Vis spectroscopy to make sure that it is completed. After cooling to room temperature, the reddish-brown material was transferred to test tubes and precipitated out of solution using $95 \%$ ethanol:water. After centrifuging and removing the ethanol, the precipitate was washed twice with methanol. The resulting solid was then further purified by flash silica gel chromatography using THF as the eluting solvent. Further purification was done by sizeexclusion chromatography with THF as the eluent. Another silica gel column on THF was run after this. The red material obtained in $66 \%$ yield $(45 \mathrm{mg}$ ) has the following characteristics indicative of the desired end product: UV-Vis $\lambda_{\max }=808 \mathrm{~nm}$; MALDI-MS $M^{+}=2360.95$. Anal. Calc. for acetate salt $\mathrm{C}_{146} \mathrm{H}_{21} \mathrm{~N}_{8} \mathrm{O}_{18} \mathrm{Mn}$ : $\mathrm{C}_{2} 73.22 ; \mathrm{H}, 8.88$; N, 4.74. Found: C, 72.92; H, 9.05; N, 4.75\%.

\subsection{Equipment}

Electrochemical experiments used a AMETEK Princeton Applied Research model 260 potentiostat. The three electrode system used for cyclic voltammetry (CV) consisted of a platinum working electrode, a platinum wire counter electrode and a homemade saturated calomel electrode (SCE) as the reference electrode. Differential pulse voltammetry (DPV) used platinum wire as working and counter electrodes, referenced to a $\mathrm{AgCl} / \mathrm{Ag}$ electrode. All data were calibrated against the ferrocenium/ferrocene couple as an internal standard. Controlled potential electrolysis used a gold foil counter electrode. Spectroelectrochemical data were collected with an Ocean Optics (Dunedin, FL 34698) HR4000 high resolution fibre optic spectrometer.

Routine UV-Vis absorption spectra were recorded on a Hewlett Packet 8452A Diode Array Spectrophotometer or with a Cary Model 2400 spectrometer. IR spectra were recorded from $\mathrm{KBr}$ disks (Analytical Grade $\mathrm{KBr}$ from Fisher Scientific) using a Thermo-Nicolet Nexus 870 FT-IR Spectrometer equipped with an air cooled MCT detector. Matrix-assisted laser desorption/ionisation timeof-flight (MALDI-TOF) mass spectra (MS) were measured using a Voyager DE-STR Biospectrometery workstation manufactured by PerSeptive Biosystems.

\section{Results and discussion}

Tetraalkoxyphthalonitriles can be readily made by nucleophilic aromatic substitution reactions of alkoxides on 3 , 4,5,6-tetrafluorophthalonitrile (1) $[9,10]$, even with very bulky alkoxides [10]. Thus treatment of 1 with neopentyl alcohol or cyclohexylmethanol in $\mathrm{N}, \mathrm{N}$-dimethylformamide 
(DMF) and $\mathrm{K}_{2} \mathrm{CO}_{3}$ at $100^{\circ} \mathrm{C}$ for $24 \mathrm{~h}$ gave $3,4,5,6$-tetraneopentoxyphthalonitrile (2) or 3,4,5,6-tetra(cyclohexylmethyloxy)phthalonitrile (3), respectively. Finally, using a variation of an old method of Linstead [19], 2 [9] or 3 was treated with the magnesium salt of 1-octanol, prepared from phenylmagnesium bromide and 1-octanol, to give, after heating for 4 days at $120^{\circ} \mathrm{C}$, hexadecaneopentoxyphthalocyaninato magnesium (4) or hexadeca(cyclohexylmethyloxy)phthalocyaninato magnesium (5). The resulting green solids were precipitated using acidified ethanol, followed by purification by silica gel and Gel-Permeation chromatography (GPC) using SX-4 beads (Bio-Rad) and toluene as the eluent. Analysis of the purified products showed that the desired products 4 or 5 were obtained, respectively. Crude magnesium-containing 4 or 5 can be demetallated by treatment in refluxing glacial acetic acid giving the metal-free hexadecaneopentoxyphthalocyanine (6) or hexadeca(cyclohexylmethyloxy)phthalocyanine (7). Treatment of 6 or 7 with excess $\mathrm{Mn}(\mathrm{OAc})_{2}$ in refluxing DMF gave the corresponding hexadecaneopentoxyphthalocyaninato manganese(III) (8) or hexadeca(cyclohexylmethyloxy)phthalocyaninato manganese(III) (9) acetates which, most surprisingly, appear as red solids, and which produced deep red solutions in organic solvents such as tetrahydrofuran (THF) (Scheme 1). The Q-band region of the UV-Vis-near IR spectrum is highly red-shifted into the near-IR region at 828 and $808 \mathrm{~nm}$ (in THF) for 8 and 9 , respectively, compared with $758 \mathrm{~nm}$ for $\mathrm{NeoPcNi}(\mathrm{II})$ [10].

As discussed below, both of these species exhibit $\mathbf{M n}^{\mathrm{II}}$ / $\mathrm{Mn}^{\text {II }}$ redox couples negative of SCE and are isolated as $\mathrm{Mn}$ (III) species. We suppose that the counter-ion is indeed acetate. Certainly there is a weak feature in the infrared spectrum of each species consistent with the presence of an acetate group; however the parent ion in the MALDI spectrum lacks the acetate residue. Both species analyse (CHN) as the PcMn ${ }^{\mathrm{III}} \mathrm{OAc}$ complexes.

\subsection{Hexadeca (cyclohexylmethyloxy) phthalocyaninato manganese(III) acetate (9) [CyHxPc(2-)Mn(OAc)]}

The cyclic voltammogram for this species in THF is shown in Fig. 1. Two reversible reduction waves are observed, but we did not observe any clean oxidation wave out to $+0.5 \mathrm{~V}$ versus $\mathrm{Fc}^{+} / \mathrm{Fc}$. Attempts to see another clean reduction process negative of $-2.0 \mathrm{~V}$ versus $\mathrm{Fc}^{+} / \mathrm{Fc}$ were not successful (see below).

Spectroelectrochemical studies shown in Figs. 2 and 3 reveal that the first reduction process corresponds with the redox process ${ }^{1} \mathrm{Pc}(2-) \mathrm{Mn}^{\mathrm{II}} / \mathrm{Pc}(2-) \mathrm{Mn}^{\mathrm{II}}$ while the second wave corresponds to $\left.\mathrm{Pc}(2-) \mathrm{Mn}^{\mathrm{II}} / \mathrm{Pc}(3-) \mathrm{Mn}^{\mathrm{II}}\right]^{-}$, i.e. formation of the radical anion. We comment below on whether the acetate ion is still bound. In keeping with the reversible behaviour shown in Fig. 1, these species can be

\footnotetext{
'Note that phthalocyanine(2-) is the normal oxidation state of the phthalocyanine ring.
}

re-oxidized quantitatively back to the parent $\mathrm{Mn}(\mathrm{III})$ species.

At the first reduction wave, the Q-band near $810 \mathrm{~nm}$ is lost and is replaced by a typical $\mathrm{Pc}(2-) \mathrm{M}$ spectrum that can readily be identified as [CyHxPc(2-)Mn $\mathrm{Mn}^{\mathrm{II}}$. The $\mathrm{Q}$ band energy for the $\mathrm{Mn}$ (II) species lies to higher energy than for the corresponding $\mathrm{Mn}$ (III) species, a typical observation for $\mathrm{PcMn}$ (II) species [20].

Further reduction at $-1.6 \mathrm{~V}$ versus $\mathrm{Fc}^{+} / \mathrm{Fc}$ (Fig. 3) yields a spectrum consistent with expectation for a $\mathrm{Pc}(3-)$ radical anion [21-24] Curiously, the absorption bands in the $700 \mathrm{~nm}$ region for this species are closely similar to those of the $\mathrm{Mn}^{\mathrm{n}}$ precursor. There is growth of a weak band near $900 \mathrm{~nm}$. The presence of the isosbestic point at $485 \mathrm{~nm}$ reveals that this is a clean reduction. These electrochemical and optical data are typical for MPc species. The neopentoxyphthalocyanine species (8), however, behaves a little differently.

\subsection{Hexadecaneopentoxyphthalocyaninato manganese(III) acetate $\left[\mathrm{NeOPc}(2-) \mathrm{Mn}^{M}(\mathrm{OAc})\right](8)$}

This species is part of a family of neopentoxyphthalocyaninato species [10]. Its electrochemical behavior, cyclic voltammetry and differential pulse voltammetry shown in Fig. 4 is significantly different from that of species (9).

The electrochemical data shown in Fig. 4 reveal reversible or quasi-reversible reduction processes (labeled II and III) at -1.69 and $-2.17 \mathrm{~V}$ versus $\mathrm{Fc}^{+} / \mathrm{Fc}$ and two reversible oxidation processes (labeled $V$ and $V I$ ) at 0.23 and 0.55 versus $\mathrm{Fc}^{+} / \mathrm{Fc}$. Reversibility is illustrated by the similarity in the forward and reverse DPV scans [25]. Between these two processes is an irreversible couple labeled I and IV.

Spectroelectrochemistry, discussed below, shows that

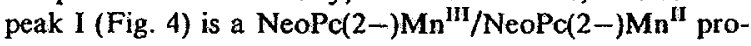
cess while peaks II and III are successive reduction processes to form $\left[\mathrm{NeoPc}(3-) \mathrm{Mn}^{\mathrm{II}}\right]^{-}$and $[\mathrm{NeoPc}(4-)$ $\mathrm{Mn}^{\mathrm{II}} \mathrm{f}^{2-}$; for the moment we ignore the question of whether, or not, an anion is bound to the manganese. To recover $\left[\mathrm{NeoPc}(2-) \mathrm{Mn}^{\mathrm{III}}\right]^{+}$one must re-oxidize at peak IV since there is no anodic counterpart to peak I. Thus there must be a chemical step following reduction at peak I to form a new $\mathrm{Mn}^{\mathrm{II}}$ species which is re-oxidized at peak IV. We return to this question below. Following re-formation of [NeoPc(2-)Mn $\left.{ }^{\text {III }}\right]^{+}$at peak IV, further oxidation occurs at peaks V and VI. The spectroelectrochemical data show that oxidation at peak $V$ forms another metal complex containing the NeoPc(2-) oxidation state; it must therefore be ascribed to metal oxidation to form $\left[\mathrm{NeoPc}(2-) \mathrm{Mn}^{1 \mathrm{~V}}\right]^{2+}$. Spectroelectrochemical evidence shows that oxidation at peak VI clearly forms a cation radical, i.e. $\left[\mathrm{NeoPc}(1-) \mathrm{Mn}^{1 \mathrm{~V}}\right]^{2+}$. These data are summarized in Table 1.

Spectroelectrochemical reduction at peak $I$ is shown in Fig. 5. A NeoPc(2-)Mn ${ }^{\text {II }}$ species is evidently formed, with close similarity to the corresponding species shown in Fig. 1. 


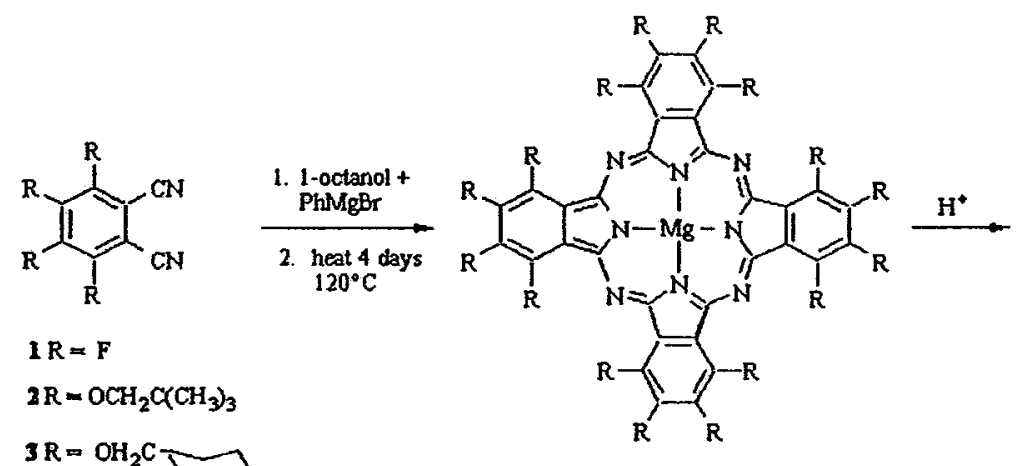

$$
\begin{aligned}
& 4 \mathrm{R}=\mathrm{OCH}_{2} \mathrm{C}\left(\mathrm{CH}_{3}\right)_{\mathrm{S}} \\
& 5 \mathrm{R}=\mathrm{OH}_{2} \mathrm{C}
\end{aligned}
$$

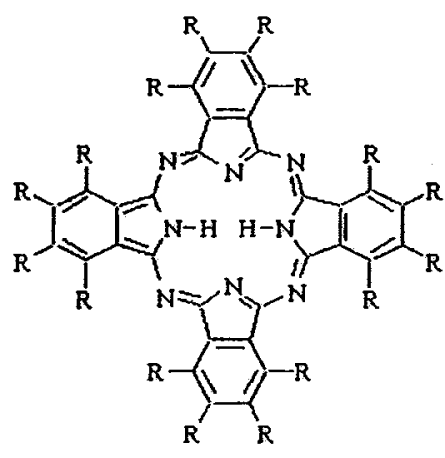

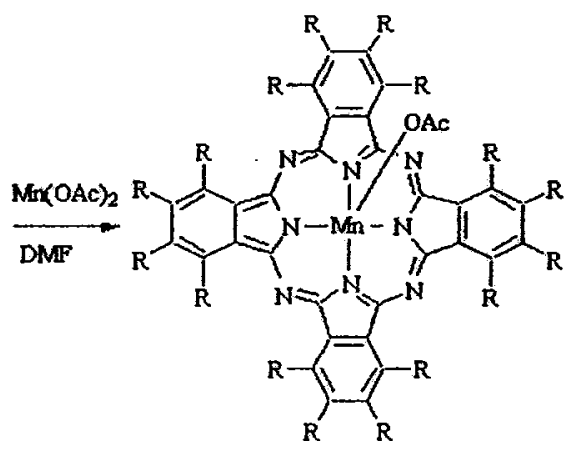

$\mathrm{G}=\mathrm{OCH}_{2} \mathrm{C}\left(\mathrm{CH}_{3}\right)_{3}$

$8 \mathrm{R}=\mathrm{OCH}_{2} \mathrm{C}\left(\mathrm{CH}_{3}\right)_{3}$

I $\mathrm{R}=\mathrm{OH}_{2}$

$\mathrm{R}=\mathrm{OH}_{2} \mathrm{C}$

Scheme I.

Reduction just negative of peak II (Fig. 6) yields a spectrum typical [21-24] of a mono-anion radical, i.e. phthalocyanine(3-) and is assigned to the formation of

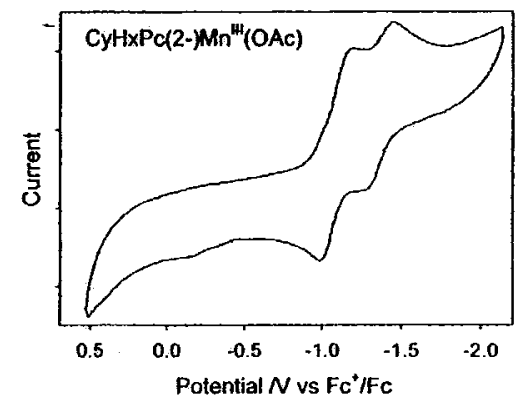

Fig. 1. Cyclic voltammogram of species (9) [CyHxPc(2-)Mn(OAc)] in THF, scan rate $100 \mathrm{mV} / \mathrm{s}$ with $0.1 \mathrm{M}$ TBAP.
$\left[\mathrm{NeoPc}(3-) \mathrm{Mn}^{11}\right]^{-}$. Subsequently, reduction just negative of peak III yields the doubly reduced phthalocyanine $\left[\mathrm{NeoPc}(4-) \mathrm{Mn}^{11}\right]^{2-}$ (see Fig. 7).

When the potential of a solution which has been reduced fully to [NeoPc(4-) $\left.\mathrm{Mn}^{\mathrm{II}}\right]^{2-}$ is reversed back to peak I, no re-oxidation occurs until the potential is poised just positive of peak IV. At this point the initial spectrum of the parent species is fully recovered. Indeed the resulting spectrum is identical with the initial spectrum which not only illustrates the reversibility of peaks I, II, III but also argues for the counter-ion which was originally present, to be recovered, i.e. the electrolyte counter-ion is not bound since it is unlikely to have provided an identical spectrum (energy and intensity of all visible region bands). Indeed we address this point again below.

Figs. 8 and 9 show the subsequent one-electron oxidation steps. The species generated in Fig. 8 is clearly that of a metal complex of phthalocyanine(2-) and must then 


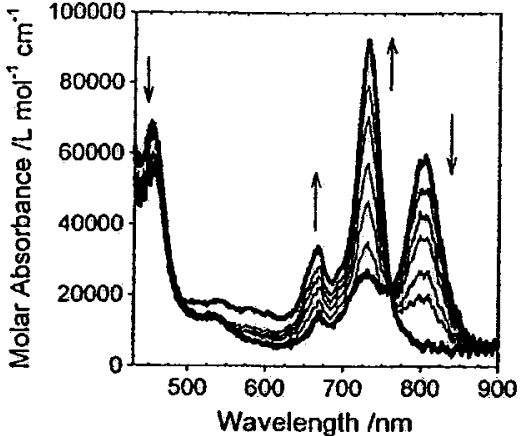

Fig. 2. Spectroelectrochemical reduction of species [CyHxPc(2-) $\mathrm{Mn}^{\mathrm{It}}$. (OAc)] (9) in THF/TBAP at ca. $-1.2 \mathrm{~V}$ vs. Fc ${ }^{+} / \mathrm{Fc}$. The spectra show the development of the reduced species over time and the formation of [CyHxPc(2-)Mn ${ }^{\mathrm{II}}$ ]. There are isosbestic points at 760 and $527 \mathrm{~nm}$. A small amount of the $\mathrm{Mn}^{\mathrm{II}}$ species exists in the initial $\mathrm{Mn}^{\mathrm{II}}$ spectrum (weak peak at $730 \mathrm{~nm}$ ). The $527 \mathrm{~nm}$ isosbestic is lost in the final spectrum which likely contains a little of the further reduced species which absorbs in the $500-600 \mathrm{~nm}$ region (see Fig. 3 ).

be assigned to a $\mathrm{Mn}^{\mathrm{IV}}$ complex, while a cation radical phthalocyanine(1-) species is generated just positive of peak VI. Given the significant basicity of the NeoPc ligand it is not surprising that a $\mathrm{Mn}^{\text {IV }}$ species can be observed.

The isosbestic points in Fig. 8 are not 'clear'; there is evidence for two $\mathrm{Mn}^{\mathrm{IV}}$ species with the second one being generated, slowly, following formation of the first-possibly a solvent molecule slowly coordinates. The chemistry was still fully reversible, as indicated by spectroelectrochemical reduction back to the parent and by the forward and reverse DPV scans (Fig. 4); the nature of the second species was not further studied.

Oxidation at peak VI yielded a spectrum (Fig. 9) typical [22-24,26] of the radical cation phthalocyanine(1-) species, and hence the formation of [NeoPc(1-) Mn ${ }^{\text {IV }}$ $(\mathrm{OAc})]^{2+}$.

Comparison of Figs. 2 and 5 shows that the spectra of the $\mathrm{Mn}(\mathrm{II}) \mathrm{Pc}(2-)$ oxidation state of both $\mathrm{NeoPc}$ and $\mathrm{CyHxPc}$ are very closely similar, including the weak

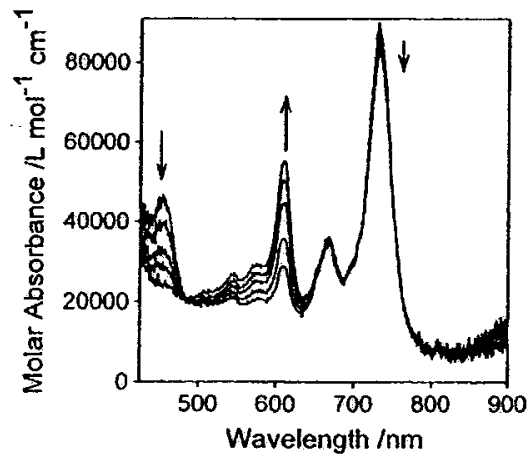

Fig. 3. Spectroelectrochemical reduction of species [CyHxPc(2-) $\mathrm{Mn}^{\mathrm{it}}$ $(\mathrm{OAc})](9)$ in THF at $\mathrm{ca} .-1.6 \mathrm{~V}$ vs. $\mathrm{Fc}^{+} / \mathrm{Fc}$. The spectra show the development of the reduced species over time and the formation of $\left[\mathrm{CyH} \mathrm{Pa}(3-) \mathrm{Mn}^{\mathrm{In}}\right]^{-}$. There is an isosbestic point at $485 \mathrm{~nm}$.

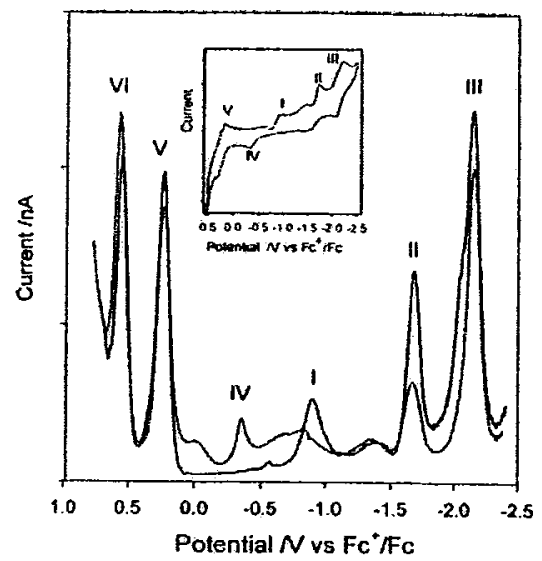

Fig. 4. Cyclic voltammetric (CV, in inset) (scan rale $100 \mathrm{mV} / \mathrm{s}$ ) and differential pulse voltammetric (DPV) (scan rate $5 \mathrm{mV} / \mathrm{s}$ ) data for species [NeoPd 2-) $\left.\mathrm{Mn}^{\mathrm{III}}(\mathrm{OAc})\right]$ (8) in tetrahydrofuran. The DPV data are shown scanning from the positive limit to the negative limit and vice versa. The scan containing peak 1 is from positive to negative and that containing IV is negative to positive.

absorption between 500 and $600 \mathrm{~nm}$ to which we return in Section 3.5. The $\mathrm{Mn}(\mathrm{II}) \mathrm{Pc}(3-)$ spectra are also largely similar with three peaks in the visible region and a weak absorption around $900 \mathrm{~nm}$.

\subsection{Variation of axial counter-ion}

During experiments to investigate the effect of excess acetate ion on a solution of these species, we discovered that adding a solution of tetrabutylammonium acetate to either of these $\mathrm{Mn}^{\mathrm{IJI}}$ species caused immediate reduction to the corresponding $\mathrm{Mn}^{\text {II }}$ species. This was evidently due to the basic nature of the tetrabutylammonium acetate solution since adding hydroxide ion had the same effect, while adding a mixture of tetrabutylammonium acetate mixed with acetic acid did not cause spontaneous reduction. If the resulting $\mathrm{NeoPc}(2-) \mathrm{Mn}^{\text {II }}$ species is acidified in air, it spontaneously reverts back to the $\mathrm{Mn}^{\mathrm{II}}$ species. This provides a means to change the counter axial anion by simply changing the acid used. The counter-ion does, as expected, have a small but noticeable effect on the spectrum

Table |

Summary of electrochemical data" in THF, $V$ vs. $\mathrm{Fc}^{+} / \mathrm{Fc}_{\mathrm{c}}$

\begin{tabular}{llll}
\hline & NeoPcMn(OAc) & NeoPcMn & CyHxPcMn(OAc) \\
\hline $\mathrm{Pc}(4-) / \mathrm{Pc}(3-)\left[\mathrm{Mn}^{\mathrm{II}}\right]$ & & -2.17 & \\
$\mathrm{Pc}(3-) / \mathrm{Pc}(2-)\left[\mathrm{Mn}^{\mathrm{II}}\right]$ & & -1.69 & -1.375 \\
$\mathrm{Mn}^{11 / 11}[\mathrm{Pc}(2-)]$ & -0.90 & -0.36 & -1.09 \\
$\mathrm{Mn}^{1 \mathrm{~V} / \mathrm{II}}[\mathrm{Pc}(2-)]$ & 0.23 & & \\
$\mathrm{Pc}(1-) / \mathrm{Pc}(2-)\left[\mathrm{Mn}^{\mathrm{IV}}\right]$ & 0.55 & &
\end{tabular}

Derived from the average peak positions of the positive and negative going DPV sweeps. 


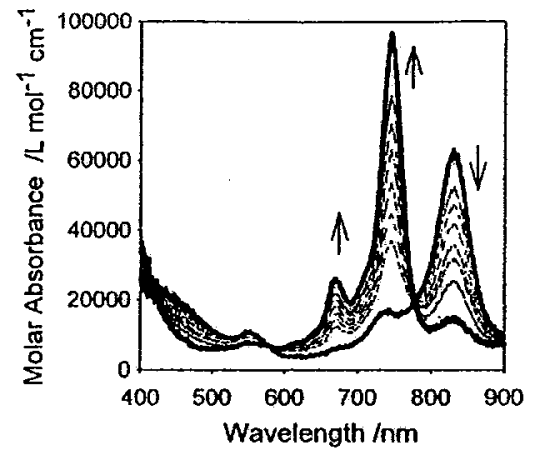

Fig. 5. Spectroelectrochemical reduction of species [NeoPc(2-) $\left.\mathrm{Mn}^{\mathrm{nt}}(\mathrm{OAc})\right]$ (8) in THF/TBAP at $-1.3 \mathrm{~V}$ vs. $\mathrm{Fc}^{+} / \mathrm{Fc}$ (just negative of peak I). The spectra show the development of the NeoPc(2-)Mn ${ }^{\text {II }}$ species over time. The initial and final spectra are bolded. There is an isosbestic point at $778 \mathrm{~nm}$. The initial $\mathrm{Mn}^{111}$ spectrum contains a little $\mathrm{Mn}^{11}$ species.

3.4. Simulation of the cyclic voltammogram of $\left[\mathrm{NeoPc}(2-) \mathrm{Mn}^{I I I}(\mathrm{OAc})\right]$ and the question of acetate binding

The electrochemical behavior of the NeoPcMn ${ }^{\text {III }}$ and $\mathrm{CyHxPcMn}{ }^{\text {III }}$ species is very different and for reasons related to acetate binding. The $\mathrm{Mn}^{\mathrm{III}} / \mathrm{Mn}^{\mathrm{II}}$ oxidation potential is sufficiently negative that the $\mathrm{Pc}(2-) \mathrm{Mn}^{\text {II }}$ species must be air sensitive and normal work up of the reaction mixture leads to a $\mathrm{Mn}^{\mathrm{III}}$ species. Analytical and FTIR evidence (in Supplementary information) is consistent with the existence of the acetate group. However acetate bound fragments do not appear in the MALDI experiment.

The CyHxPcMn ${ }^{\text {III }}$ (OAc) cyclic voltammogram (Fig. 1) looks perfectly 'normal' and reversible and would then be consistent with the acetate remaining bound to the $\mathrm{Mn}$ atom during the first two reduction processes.

However, it is clear (Fig. 4) that in the case of the $\mathrm{NeoPc}(2-) \mathrm{Mn}^{\prime \prime \prime}$ (OAc) species, the initial reduction to the $\mathrm{Mn}^{\text {Il }}$ state is irreversible. The most simple explanation is

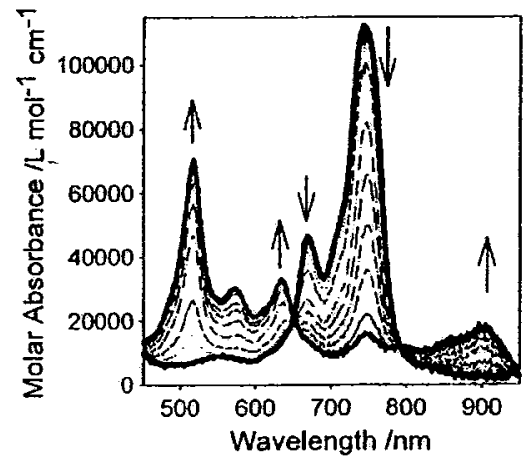

Fig. 6. Spectroelectrochemical reduction of species [NeoPc(2-) $\left.\mathrm{Mn}^{\text {'III }}(\mathrm{OAc})\right](8)$ in THF/TBAP at $-1.90 \mathrm{~V}$ vs. $\mathrm{Fc}^{+} / \mathrm{Fc}$, just negative of peak II. The spectra show the development of the species [NeoPc(3-) Mn ${ }^{\mathrm{II}}$ ] over time. Initial and final spectra are bolded. Isosbestic points are seen at 444,651 and $794 \mathrm{~nm}$.

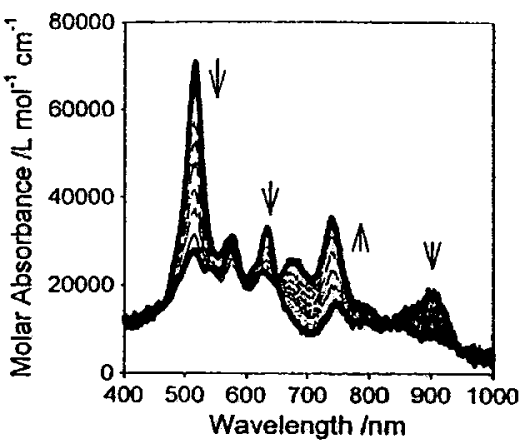

Fig. 7. Spectroelectrochemical reduction of species [NeoPc/2-) $\mathrm{Mn}^{\mathrm{III}}$. (OAc)] (8) in THF/TBAP at $-2.4 \mathrm{~V}$ vs. $\mathrm{Fc}^{+} / \mathrm{Fc}$, just negative of peak III The spectra show the development of the $\left[\mathrm{NeoPc}(4-) \mathrm{Mn}^{13}\right]^{2-}$ species over time. Initial and final spectra are bolded. Isosbestic points are seen at 654 and $832 \mathrm{~nm}$.

that the acetate ion is released upon reduction to $\mathrm{Mn}^{\mathrm{II}}$ and that the rate of loss is very fast, i.e. the equilibrium for the process (1) lies very much to the right:

$\left[\mathrm{NeoPc}(2-) \mathrm{Mn}^{\mathrm{Il}}(\mathrm{OAc})\right]^{-} \Longleftrightarrow\left[\mathrm{NeOPc}(2-) \mathrm{Mn}^{\mathrm{II}}\right]+\mathrm{OAc}^{-}$

It will be more difficult to oxidize [NeoPc(2-) $\left.\mathrm{Mn}^{\mathrm{II}}\right]$ back to the $\mathrm{Mn}^{\mathrm{III}}$ state than to oxidize [NeoPc(2-) $\left.\mathrm{Mn}^{\mathrm{II}}(\mathrm{OAc})\right]^{-}$ back to $\mathrm{Mn}^{\mathrm{II}}$; thus it is reasonable to associate peak I with the process:

$$
\begin{aligned}
& {\left[\mathrm{NeoPc}(2-) \mathrm{Mn}^{\prime \prime \prime}(\mathrm{OAc})\right]} \\
& +\mathrm{e}^{-} \Longleftrightarrow\left[\mathrm{NeoPc}(2-) \mathrm{Mn}^{\prime \prime}(\mathrm{OAc})\right]^{-} \quad \text { (couple 1) }
\end{aligned}
$$

followed immediately by reaction (1), i.e. an EC process [25].

While peak IV is:

$\left[\mathrm{NeoPc}(2-) \mathrm{Mn}^{\prime \prime}\right] \Longleftrightarrow\left[\mathrm{NeoPc}(2-) \mathrm{Mn}^{\mathrm{III}}\right]^{+}+\mathrm{e}^{-}$(peak IV)

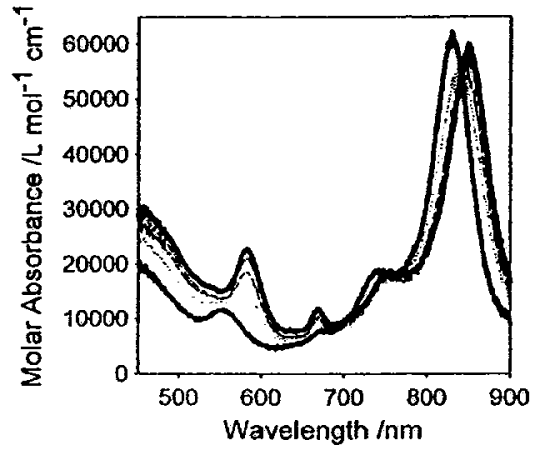

Fig. 8. Spectroelectrochemical oxidation of species [NeoPc(2-) Mn ${ }^{\mathrm{In}}$ (OAc)] (8) in THF/TBAP at $+0.40 \mathrm{~V}$ vs. $\mathrm{Fc}^{+} / \mathrm{Fc}$, just positive of peak $\mathrm{V}$. The spectra show the development of the $\left[\mathrm{NeOPc}(2-) \mathrm{Mn}^{1 \mathrm{~V}}-(\mathrm{OAc})\right]^{+}$ species over time. Initial and final spectra are bolded. NB The final spectrum has the longer wavelength $Q$-band and is the upper spectrum on the short wavelength side. 


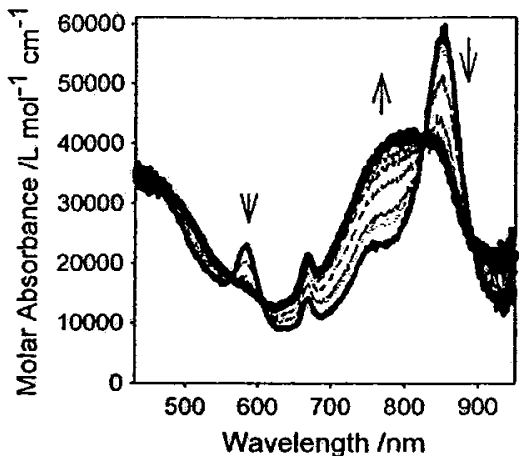

Fig. 9. Spectroelectrochemical oxidation of species [NeoPc(2-) Mn ${ }^{\text {IV }}$ (OAc)] (8) in THF/TBAP at $+0.80 \mathrm{~V}$ vs. $\mathrm{Fc}^{+} / \mathrm{Fc}$, just positive of peak $\mathrm{V}$. The spectra show the development of the $\left[\mathrm{NeoPc}(1-) \mathrm{Mn}^{3 \mathrm{~V}}(\mathrm{OAc})\right]^{2+}$ species over time. Initial and final spectra are bolded. Isosbestic points are seen at 563,608 and $823 \mathrm{~nm}$.

followed by a very rapid chemical reaction, with the equilibrium lying strongly to the right:

$\left[\mathrm{NeoPc}(2-) \mathrm{Mn}^{\mathrm{III}}\right]^{+}+\mathrm{OAc}^{-} \Longleftrightarrow\left[\mathrm{NeoPc}(2-) \mathrm{Mn}^{\mathrm{III}}(\mathrm{OAc})\right]$

Thus peak IV is an EC process [25]. This mechanism can be simulated and the resulting $C V$ is shown in Fig. 10 with details of the parameters in Appendix A. Indeed to satisfactorily explain the voltammogram, the equilibria (1) and (4) must lie strongly to the right meaning that the forward rate constants are very fast. We do not imply that the actual values reported in Appendix A are 'correct' for this system, but they should be qualitatively correct.

Note that this mechanism requires that the acetate remain bound during the oxidation processes $\mathrm{V}$ and $\mathrm{VI}$. This must be so because of the reversibility of these processes and the fact that one sees the same potentials independent of the direction of scanning. This is not surprising since the increasing positive charge will increase the binding constant for acetate ion.

Nominally, reduction processes $I I$ and III then involve formation of the $\mathrm{Pc}(3-) \mathrm{Mn}^{\mathrm{II}}$ and $\mathrm{Pc}(4-) \mathrm{Mn}^{\mathrm{II}}$ species lacking bound acetate, namely:

$$
\begin{aligned}
& \operatorname{NeoPc}(2-) \mathrm{Mn}^{\mathrm{II}} \\
& \quad+\mathrm{e}^{-} \Longleftrightarrow\left[\mathrm{NeoPc}(3-) \mathrm{Mn}^{\mathrm{II}}\right]^{-} \quad \text { (peak II) } \\
& \text { and } \\
& {\left[\mathrm{NeoPc}(3-) \mathrm{Mn}^{\mathrm{II}}\right]^{-}} \\
& +\mathrm{e}^{-} \Longleftrightarrow\left[\mathrm{NeoPc}(4-) \mathrm{Mn}^{\mathrm{II}}\right]^{2-} \quad \text { (peak III) }
\end{aligned}
$$

The simulation assumes this case. However, the simulation differs from the experiment in that there are some additional features between peaks I and II, and we were never able to see peak II as fully reversible despite care to dry the solvent. There is an additional process that ought to be considered, namely (7):

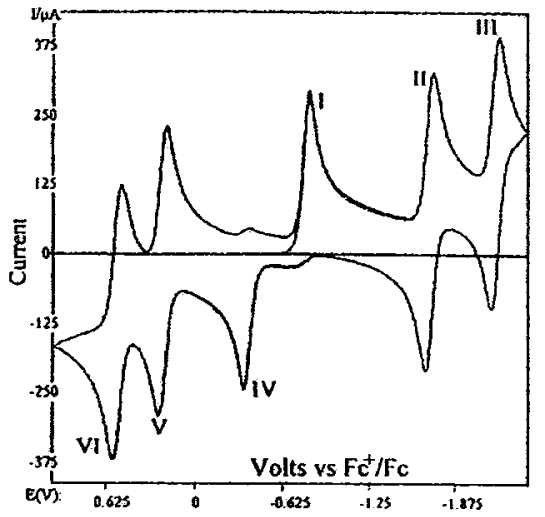

Fig. 10. Simulation of the cyclic voltammogram of $[\mathrm{NeoPc} 2-) \mathrm{Mn}^{\mathrm{II}}$. (OAc)] in Fig. 4. Mechanism and parameters used are described in Appendix A.

$$
\begin{aligned}
& {\left[\mathrm{NeoPc}(2-) \mathrm{Mn}^{\mathrm{II}}(\mathrm{OAc})\right]^{-}} \\
& +\mathrm{e}^{-} \Longleftrightarrow\left[\mathrm{NeoPc}(3-) \mathrm{Mn}^{\prime \prime}(\mathrm{OAc})\right]^{2-}
\end{aligned}
$$

where one may consider that reaction (1) is not so fast and there can be some contribution from process (7). We suppose that the potential for this reaction will be more negative than process (5) but it is evidently not very important and was not included in the theoretical analysis.

\subsection{Why are these $M n(I I I)$ species red?}

Most Pc species are blue because the intense Q-band usually lies at the red end of the visible spectrum and absorbs the red light so that the transmitted light appears blue or green. In these complexes, the Q-band is shifted out of the visible region so that the color of the complex is now determined by the absorption at the blue end of the spectrum; hence they appear red. Previous experiments with hexadecaneopentoxyphthalocyaninato nickel(II) revealed a $Q$-band at $758 \mathrm{~nm}[10]$ well to the red of the $Q$ bands of most phthalocyanine species. The parent Mn(III) phthalocyanine (unsubstituted) species absorbs near $720 \mathrm{~nm}$ depending on axial groups [20], also to the red of most other parent MPc species. It is therefore consistent that the NeoPc(2-)Mn(III) species will absorb more to the red than the nickel analog.

The red shift must be due to the action of the 16 neopentoxy groups but is it due to their electronic interaction with the phthalocyanine ring, or to the steric impact of these groups, causing ring buckling. INDO, in the Zerner manifestation, ZINDO [27-32] has proven to be a good theoretical vehicle to calculate MPc electronic spectra [33]. Since the Mn species is an open shell species, we opted to carry out an INDO analysis of the closed shell, square planar NeoPc(2-) Ni(II) [10]. INDO geometry optimization led to a good structure in which the ring remains essentially planar. Thus within this formalism, the neopentoxy 


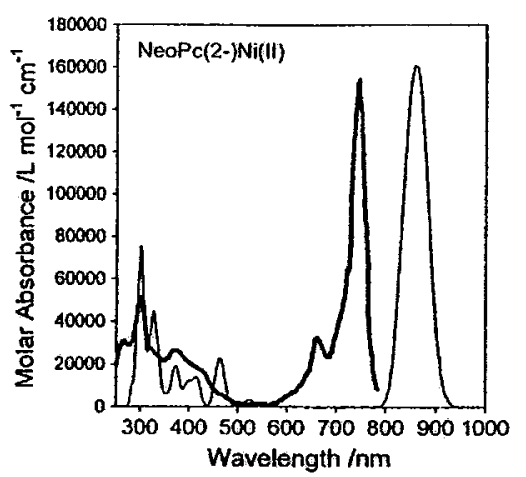

Fig. 11. Experimental data for hexadecaneopentoxyphthalocyaninatonickel(II) in THF (thick line) compared with the INDO/S calculated spectrum (thin line).

groups do not induce ring buckling. Most importantly, as shown in Fig. 11, the INDO/S calculated electronic spectroscopic energies are in remarkably good agreement with experiment, and the relative intensities of the various bands, agree reasonably well. The difference in the calculated and experimental Q-band energies, while it may look considerable in the figure, is less than $2000 \mathrm{~cm}^{-1}$.

In particular note that the broad structured band near $400 \mathrm{~nm}$ is evidently due to a collection of overlapping transitions. Most of these transitions are $\pi-\pi^{*}$ within the $\mathrm{Pc}$ ring framework, but there is a predicted $\mathrm{Pc} \rightarrow \mathrm{Ni}(3 \mathrm{~d})$ LMCT transition [34] of relatively large intensity predicted to lie in the $400 \mathrm{~nm}$ region.

INDO/S exaggerates the absolute intensity and so the calculated value is scaled down by a factor of 6 . No attempt was made, in the INDO/S calculation, to include the vibrational coupled transition near $680 \mathrm{~nm}$. In the simulation, a bandwidth of $580 \mathrm{~cm}^{-1}$ was used for the Q-band and $1000 \mathrm{~cm}^{-1}$ for all other bands. A value somewhat larger than $1000 \mathrm{~cm}^{-1}$, in the $350-500 \mathrm{~nm}$ range would better simulate the broad overlapping experimental data in that region.

One may then suppose that some of the broad absorption near $400 \mathrm{~nm}$ in the $\mathrm{Mn}$ (III) species is also LMCT in origin, probably from deeper lying filled $\pi$-orbitals.

\section{Conclusion}

In this paper, we have demonstrated that very bulky metal-free, magnesium, and manganese hexadecaalkoxysubstituted phthalocyanines can be synthesized. These species have $Q$ bands well to the red of most other MPc species. An INDO analysis led us to conclude that the ring is probably not buckled and that the electronic effect of the 16 alkoxy groups was responsible for the significant shift to the red, of the Q-band energy. It is well known that $\mathrm{PcMn}^{\mathrm{II}}$ compounds tend to have much longer wavelength $\mathrm{Q}$ bands than most other simple $\mathrm{Pc}(2-) \mathrm{M}$ species. Thus the highly red shifted absorption spectra of the $\mathrm{Mn}$ (III) species
Table 2

Summary of optical data in THF containing TBAP, in nm

\begin{tabular}{|c|c|}
\hline Species & Absorption maxima $(\log \varepsilon)$ \\
\hline $\begin{array}{l}{\left[\mathrm{NeoPc}(1-) \mathrm{Mn}^{\mathrm{IV}}(\mathrm{OAc})\right]^{2+}} \\
{\left[\mathrm{NeoPc}(2-) \mathrm{Mn}^{\mathrm{IV}}(\mathrm{OAc})\right]^{+}}\end{array}$ & $\begin{array}{l}829 \text { br }(4.62), 669(4.33), 584 \text { sh } \\
849(4.78), 756(4.28), 666(4.06), 584(4.36)\end{array}$ \\
\hline $\mathrm{NeoPc}(2-) \mathrm{Mn}^{\mathrm{II}}$ (OAc) & $\begin{array}{l}827(4.80), 740(4.20), 570(4.15), 465 \mathrm{sh} \\
413(4.40)\end{array}$ \\
\hline NeoPc(2-)Mn" & $744(5.05), 669(4.67), 546(3.96), 411(4.19)$ \\
\hline$\left[\mathrm{NeoPc}(3-) \mathrm{Mn}^{\mathrm{II}}\right]^{-}$ & $\begin{array}{l}910(4.26), 745(4.21), 634(4.52) \\
572(4.48), 517(4.85)\end{array}$ \\
\hline$\left[\mathrm{NeOPC}(4-) \mathrm{Mn}^{\mathrm{II}}\right]^{2-}$ & $\begin{array}{l}741(4.04), 680(4.41), 628(4.37) \\
578(4.49), 546 \mathrm{sh}, 516(4.45)\end{array}$ \\
\hline $\mathrm{CyH} \mathrm{HPc}\left(2-3 \mathrm{Mn}^{\mathrm{III}}(\mathrm{OAc})\right.$ & $800(4.76), 721(4.40), 528(4.17), 453(4.84)$ \\
\hline$\left[\mathrm{CyH} \times \mathrm{PC}(2-) \mathrm{Mn}^{\mathrm{II}}(\mathrm{OAc})\right]$ & $730(4.97), 667(4.53), 450(4.76)$ \\
\hline$\left[\mathrm{CyHxPc}(3-) \mathrm{Mn}^{21}(\mathrm{OAc})\right]^{\mathrm{T}^{-}}$ & $732(4.92), 667(4.56), 570(4.47), 546(4.43)$ \\
\hline
\end{tabular}

is not unexpected. They are of especial interest because while phthalocyanines are usually blue or green in color, the $\mathrm{Mn}^{\text {III }}$ species are red since the $\mathrm{Q}$ band absorption is shifted out of the visible spectrum.

Electrochemical data are reported for both species. The electrochemistry of the $\mathrm{NeoPc}(2-) \mathrm{Mn}^{1{ }^{11}}$ (OAc) species is rather unusual but can be explained in terms of several acetate binding equilibria which were simulated. Spectroelectrochemical data allowed the characterization of a range of different oxidation states in solution, including some $\mathrm{Pc}(1-) \mathrm{Mn}^{\mathrm{IV}}, \mathrm{Pc}(2-) \mathrm{Mn}^{\mathrm{IV}}, \mathrm{Pc}(3-) \mathrm{Mn}^{11}$ and $\mathrm{Pc}(4-) \mathrm{Mn}^{\mathrm{I}}$ species (see Table 2).

\section{Acknowledgement}

The authors thank the Natural Sciences and Engineering Research Council of Canada for Discovery Grants in aid of this research.

\section{Appendix A}

The electrochemical simulation employed DIGIsIM, version 3.03 (BAS Instruments Ltd., West Lafayette, IN 47906). The following mechanism and parameters were required to simulate the voltammogram shown in Fig. 10.

The overall mechanism is displayed in Eqs. (8)-(16). $\mathrm{Pc}(2-)$ etc. are abbreviations for the NeoPc ligand. Eqs. $(8),(9),(12)-(15)$ display the redox processes I-VI with potentials identified in Table 1. Eq. (10) describes the binding of acetate to the bare $\mathrm{NeoPc}(2-) \mathrm{Mn}^{\text {III }}$ fragment while Eq. (11) describes the loss of acetate ion from $\left[\mathrm{NeoPc}(2-) \mathrm{Mn}^{\mathrm{II}} \mathrm{OAc}\right]^{-}$. The equilibrium constant shown in italics in Eq. (11) is dependent on the other input parameters and is not independently variable. The $K_{\text {Eq. }}$ value in Eq. (10) and the forward rate constants in Eqs. (10) and (11) were varied to reproduce the overall features of the experimental voltammogram. The key requirement was that processes I and IV were essentially irreversible. It was assumed that the $\mathrm{Mn}^{\mathrm{IV}}$ and $\mathrm{Mn}^{\mathrm{V}}$ species in Eqs. (12) and (13) would bind acetate so strongly that equations 
describing its loss, on the time scale of the voltammetry, were unnecessary. Further, to keep the mechanism as simple as possible, the binding of acetate ion to $\mathrm{NeoPc}(3-)$ $\mathrm{Mn}^{\mathrm{II}}$ was considered negligible.

$$
\begin{aligned}
& \mathrm{Pc}(2-) \mathrm{Mn}^{\mathrm{II}} \mathrm{OAc}+\mathrm{e}^{-}=\mathrm{Pc}(2-) \mathrm{Mn}^{11} \mathrm{OAc} \\
& E_{0}=-0.90 \text { (I) } \\
& \mathrm{Pc}(2-) \mathrm{Mn}^{\mathrm{II}}+\mathrm{e}^{-}=\mathrm{Pc}(2-) \mathrm{Mn}^{\mathrm{Il}} \quad E_{\mathrm{o}}=-0.36 \mathrm{~V} \text { (IV) } \\
& \mathrm{Pc}(2-) \mathrm{Mn}^{\mathrm{III}}+\mathrm{OAc}^{-}=\mathrm{Pc}(2-) \mathrm{Mn}^{\mathrm{II}} \mathrm{OAc} \\
& K_{\mathrm{Eq} .}=1 \times 10^{6} ; k_{\mathrm{f}}=1 \times 10^{4} \\
& \mathrm{Pc}(2-) \mathrm{Mn}^{\mathrm{Il}} \mathrm{OAc}=\mathrm{Pc}(2-) \mathrm{Mn}^{\mathrm{Il}}+\mathrm{OAc}^{-} \\
& K_{\mathrm{Eq} .}=1337 ; k_{\mathrm{r}}=1 \times 10^{4} \\
& \mathrm{Pc}(2-) \mathrm{Mn}^{\mathrm{IV}} \mathrm{OAc}+\mathrm{e}^{-}=\mathrm{Pc}(2-) \mathrm{Mn}^{\mathrm{II}} \mathrm{OAc} \\
& E_{\mathrm{o}}=0.23 \mathrm{~V}(\mathrm{~V}) \\
& \mathrm{Pc}(1-) \mathrm{Mn}^{\mathrm{IV}} \mathrm{OAc}+\mathrm{e}^{-}=\mathrm{Pc}(2-) \mathrm{Mn}^{\mathrm{IV}} \mathrm{OAc} \\
& E_{\mathrm{o}}=0.55 \mathrm{~V}(\mathrm{VI}) \\
& \operatorname{Pc}(2-) \mathrm{Mn}^{\mathrm{Il}}+\mathrm{e}^{-}=\mathrm{Pc}(3-) \mathrm{Mn}^{\prime \prime} \quad E_{0}=-1.69 \mathrm{~V} \text { (II) } \\
& \mathrm{Pc}(3-) \mathrm{Mn}^{\mathrm{II}}+\mathrm{e}^{-}=\mathrm{Pc}(4-) \mathrm{Mn}^{\mathrm{II}} \quad E_{\mathrm{o}}=-2.17 \mathrm{~V} \text { (III) } \\
& \text { Bulk } \mathrm{Pc}(2-) \mathrm{Mn}^{\mathrm{III}} \mathrm{OAc} 1 \times 10^{-3} \mathrm{M}
\end{aligned}
$$

Scan rate $100 \mathrm{mV} / \mathrm{s}$.

Other parameters used to create the simulation in Fig. 10 were, for all species: Diffusion coefficient $1 \times 10^{-5} \mathrm{~cm}^{2} \mathrm{~s}^{-1}$; heterogeneous rate constant $1 \times 10^{4} \mathrm{~cm} \mathrm{~s}^{-1}$; transfer coefficient $0.5 \mathrm{eV}$.

\section{Appendix B. Supplementary data}

Supplementary data associated with this article can be found, in the online version, at doi:10.1016/j.ica.2005.10. 046 .

\section{References}

[1] C.C. Leznof, A.B.P. Lever (Eds.), The Phthalocyanines, Properties and Applications, VCH, New York, 1989-1996.

[2] N.B. McKeown, in: Phthalocyanines Materials - Synthesis, Structure and Function, Cambridge University Press, New York, 1998

[3] N. McKeown, Comprehensive Coordination Chemistry II, Elsevier Science Publishers, Amsterdam, 2003.
[4] N. KobayashiThe Phthalocyanines, Properties and Applications, vol. 2, VCH Publishers Inc., New York, 1993, p. 97.

[5] A.K. Sobbi, D. Wöhrle, D. Schfettwein, J. Chem. Soc., Perkin Trans. 2 (1993) 481 .

[6] P.J. Duggan, P.F. Gordon, Eur. Pat. Appl. EP155780, 1985

[7] C.C. Leznoff, in: C.C. Leznoff, A.B.P. Lever (Eds.), Phthalocyanines: Properties and Apptications, vol. I, VCH, New York, 1989, p. I.

[8] M.J. Cook, A.J. Dunn, S.D. Howe, A.J. Thomson, J. Chem. Soc., Perkin Trans. 1 (1988) 2453.

[9] W. Eberhardt, M. Hanack, Synthesis (1997) 95.

[10] N. Bhardwaj, J. Andraos, C.C. Leznoff, Can. J. Chem. 80 (2002) 141.

[11] C.-H. Lee, D.K.P. Ng, Tetrahedron Lett. 43 (2002) 4211.

[12] H. Uchida, P.Y. Reddy, S. Nakamura, T. Toru, J. Org. Chem. 68 (2003) 8736.

[13] A. Shaabani, N. Safari, A. Bazgir, F. Bahađoran, N. Shafiri, P.R. Jamaat, Synth. Commun. 33 (2003) 1717.

[14] M.N. Kopylovich, V.U. Kukushkin, M. Haukka, K.V. Luzyanin, A.J.L. Pombeiro, J. Am. Chem. Soc. 126 (2004) 15040.

[15] A.B.P. Lever, C.C. Leznof, Red phthalocyanines. $60 / 474,300,30$ May 2003.

[16] A.B.P. Lever, C.C. Leznoff PCT/CA2004/000808 (W02004/106436 A/), 30 May 2004

[17] P.M. Burnham, M.J. Cook, L.A. Gerrard, M.J, Heeney, D.L Hughes, J. Chem. Soc., Chem. Commun. (2003) 2064.

[18] T. Fukuda, K. Ono, S. Homma, N. Kobayashi, Chem Lett. (2003) 736.

[19] R.P. Linstead, A.R. Lowe, J. Chem. Soc. (1934) 1022

[20] A.B.P. Lever, Adv. Inorg. Chem. Radiochem. 7 (1965) 27.

[21] J. Mack, M.J. Stillman, J. Porphyrins Phthalocyanines 5 (2001) 67.

[22] E. Ough, Z. Gasyna, M.J. Stillman, Inorg. Chem. 30 (1991) 2301

[23] M. L'Her, A. Pondaven The Porphyrin Handbook, vol. 16, Academic Press, New York, 2003.

[24] S.P. Keizer, W. Han, M.J. Stillman, Inorg. Chem. 41 (2002) 353

[25] A.J. Bard, L.R. Faulkner, Electrochemical Methods: Fundamentals and Applications, 2nd ed., Wiley, New York, 2001.

[26] J. Mack, M.J. Stillman, Inorg. Chem. 40 (2001) 812

[27] J.D. Baker, M.C. Zerner, J. Phys. Chem. 95 (1991) 8614.

[28] J. Ridley, M.C. Zerner, Theor. Chim. Acta 42 (1976) 223.

[29] J. Ridley, M.C. Zerner, Theor. Chim. Acta 32 (1973) 111.

[30] C. Martin, M.C. Zerner, in: E.I. Solomon, A.B.P. Lever (Eds.), Inorganic Electronic Structure and Spectroscopy, vol. 1, Wiley, New York, 1999 , p. 555.

[31] M.C. Zerner, in: N. Russo, D.R. Salahnb (Eds.), Metal-Ligand Interactions, Kluwer Academic Publishers, Dordrecht, 1996, p. 493.

[32] M.C. ZernerReviews In Computational Chemistry, vol. 2, VCH Publishers, New York, 1991, p. 313.

[33] N. Kobayashi, H. Ogata, T. Fukuda, S.-I. Nakajima, Chem.-Eur. J $10(2004) 6294$.

[34] A.B.P. Lever, S.R. Pickens, P.C. Minor, S. Licoccia, B.S. Ramaswamy, K. Magneil, J. Am. Chem. Soc. 103 (1981) 6800. 